\title{
Cuatro ciudades chinas: transición y cambio social
}

$\mathrm{E}$ 1 viajero que arribe a China con la idea mística de la China imperial o aun de la China maoísta quedará decepcionado. Hoy en día, además de los distintos amuletos con la fotografía de Mao -que todo chofer debe llevar-y de los templos y monasterios esparcidos por todo el país, queda cada vez menos de aquella China. Los principales puertos aéreos de entrada -Shanghai y Pekín- son el mejor ejemplo de esto; la modernidad de estas ciudades puede compararse con la de cualquier otra metrópoli en el mundo. Los modernos aeropuertos, las amplias vías rápidas y los rascacielos son común denominador de sus principales ciudades.

A través de la descripción de cuatro ciudades chinas -Hangzhou, donde resido ahora, Shanghai, Pekín y Taiyuán- buscaré explicar algunas de las problemáticas del país en reforma, tratando de desmitificar algunas de las críticas que se han hecho en el extranjero, ubicándolas en el contexto chino.

\section{Antecedentes}

Nos encontramos quizá con el proceso de reforma y crecimiento económico más rápido del último siglo; un proceso implementado en 1978 después de más de una década de confrontaciones políticas. Durante los ochenta la reforma tuvo sus altibajos, pero aun así el crecimiento económico siguió su marcha. La década de los noventa representó el boom económico y del comercio. China comerciaba cada vez con un número mayor de países, al igual que recibía una cantidad creciente de inversión extranjera. Y con la inversión y el comercio llegaron las

* Investigadora del Departamento de Estudios del Pacífico de la Universidad de Guadalajara. transnacionales, las películas de Hollywood, las marcas extranjeras de todo tipo de productos. Después del viaje al sur de Deng Xiaoping en 1992, durante el cual expresó su ya famosa frase 'Hacerse rico es glorioso', el socialismo en China comenzó a ser sinónimo de modernidad.

\section{Shanghai}

China es un país en desarrollo, literalmente en desarrollo. No hay ciudad china en donde no se esté construyendo un edificio nuevo, un puente nuevo, una nueva carretera o un nuevo aeropuerto. Existe el chiste entre extranjeros de que es imposible encontrar casa o departamento en donde no se esté construyendo algo al lado, y en donde el martilleo y demás ruidos de la construcción no cesen ni por la madrugada.

La primera vez que visité Shanghai fue en 1996, la ciudad estaba plagada de grúas de construcción, y en la zona de Pudong -frente al viejo Shanghai- sólo se veía entonces la impresionante Torre Perla, actual símbolo de la ciudad. Regresar dos años más tarde fue como visitar una nueva ciudad. Sin embargo, es quizá ahora cuando Shanghai se ha convertido realmente en la más grande metrópoli de China. Después de haber estado en el viejo aeropuerto, al llegar al nuevo de Pudong uno no puede creer el cambio tan impresionante. Shanghai está plagado ahora de rascacielos, mientras que en Pudong se ha construido ya un edificio más alto que la propia Torre Perla. ¡Este edificio alberga oficinas de empresas extranjeras y chinas y un lujoso hotel cuyo lobby se encuentra en el piso 52 !

Sin embargo, el cambio y la modernidad no sólo se aprecian en la arquitectura local y los 
miles de anuncios espectaculares de empresas extranjeras y nacionales. Mientras que en 1998 uno podía ser seguido por más de un chino curioso, hoy en día ver extranjeros en la calle es tan común que los shanghaineses ya no se molestan en voltear. Otros indicadores del cambio son la forma de vestir (al ritmo de la moda internacional) y los hábitos de consumo (los shanghaineses también aman el shopping y comer en restaurantes de moda, desde comida japonesa, alemana, francesa y hasta McDonald's). Otro indicador es la cultura: los museos de arte de Shanghai han expuesto no sólo a los artistas chinos más prestigiados, sino que han traído exposiciones de artistas de fama internacional. Al tiempo que escribo esto se exponen en el Museo de Arte de Shanghai obras de Salvador Dalí y una colección de fotografías de Frida Kahlo tomadas por Lola Álvarez Bravo.

La construcción y el auge económico de esta ciudad atrajo a gran número de personas provenientes de distintas provincias. De tal magnitud ha sido la migración a Shanghai que se ha establecido que la población flotante (es decir las personas que viven en la ciudad sin un carnet de residencia o hukou urbano) alcanza ya los 2 millones de personas. La migración interna ha sido también una de las consecuencias de la reforma económica. Hasta 1978 cambiar de residencia -del campo a la ciudad o de una ciudad a otra- era casi imposible. Un hukou urbano era hasta entonces -y aun hoy en día, pero en menor grado- significado de diferentes privilegios: empleo vitalicio, vivienda y servicios médicos gratuitos y una pensión. En el campo algunos de estos servicios eran ofrecidos por las cooperativas, aunque muchas de la veces con fondos otorgados por los propios campesinos.

El relajamiento del sistema de registro (hukou) dio la oportunidad a la gente del campo de migrar a las ciudades; esta migración por lo general no fue un movimiento permanente, sino más bien un movimiento temporal que permitía aumentar el ingreso de las familias campesinas. Se estima que para mediados de los noventa entre 80 y 100 millones de personas (¡la población total de Mexico!) se encontraban trabajando lejos de su lugar de origen. Estos migrantes no han sido siempre bien recibidos por la sociedad urbana. Se les ha acusado de los crecientes índices de delincuencia, de ser un costo y carga para los servicios públicos de la ciudad y de quitar trabajos a los residentes locales. El reciente desempleo, resul-tado de la reestructuración de las empresas estatales, ha acrecentado estos resenti-mientos para con los migrantes. La mayoría de estos, carentes de un hukou urbano, han tenido que organizarse para no ser víctimas de los abusos de la policía y para poder sobrellevar las pobres condiciones de trabajo y de vida.

\section{Pekín}

Fue también en 1996 cuando conocí por primera vez Pekín. Capital imperial de varias dinastías, Pekín mantiene dentro de la modernidad su estilo tradicional. Hacia la puerta sur de la Ciudad Prohibida se encuentra la Plaza de Tiananmen, mayor que el Zócalo de la ciudad 
de México y que la Plaza Roja de Moscú. Desde la plaza se observa la gran fotografía de Mao Zedong y al centro de la plaza se encuentra su mausoleo.

El Pekín actual es una ciudad limpia, renovada, moderna y a la vez llena de tradición, en gran parte resultado del esfuerzo para conseguir la sede de las olimpiadas en el 2008. Por todos lados se encuentra el emblema 'Beijing 2008'; las calles han sido repavimentadas, los edificios remodelados y muchos más han sido construidos. Mientras que en Shanghai gran parte de los extranjeros son gente de negocios, en Pekín abunda también el turismo recreativo. Gente de todos los confines viene a visitar la Gran Muralla y la Ciudad Prohibida.

En mi última visita a Pekín conocí a otro curioso tipo de turistas. En el hotel en que nos hospedamos un grupo de parejas españolas, todas con carriolas, enseñaban a sus recién adoptadas hijas chinas sus primeras palabras de español. Muy conocida es ya la política de control demográfico que restringe a los parejas chinas a tener un solo hijo, y hasta dos para familias pertenecientes a una minoría étnica. Si bien esta política ha logrado reducir el crecimiento poblacional, ha traído también consecuencias sociales no previstas. La política de un solo hijo afectó sobre todo a las familias (en especial a las mujeres campesinas). La tradición y una lógica económica habían llevado a las parejas campesinas a tener varios hijos. Especial interés había en tener al menos un hijo varón, el cual no sólo mantendría el apellido de la familia, sino que podría ser el sustento de los padres cuando envejecieran; por otro lado, las hijas perdían el apellido al casarse, además de que pasaban a ser parte de la familia del esposo.

Las mujeres pronto comenzaron a verse presionadas a concebir hijos varones, con sólo una o dos oportunidades para obtenerlo. La presión fue tal que muchas mujeres llevaron a cabo abortos provocados, después de que un ecosonograma les mostrara el feto de una niña. Otras nunca pudieron concebir un hijo varón y fueron golpeadas por sus esposos, muchos de los cuales decidieron divorciarse. Otras tantas abandonaron a sus bebés niñas o las entregaron a orfanatorios. Recientemente dos reconocidos psiquiatras están llevando a cabo una investigación sin precedente sobre el suicidio en China. Uno de los resultados arrojados por su investigación es que la mayor parte de los suicidios reportados en China son casos de mujeres que viven en zonas rurales ${ }^{1}$. De igual manera, la política de un solo hijo y la preferencia por los hijos varones, ha causado una desproporción entre el número de varones y mujeres: en 1995, por cada 100 niñas $^{2}$ nacían 117.4 niños, muy por arriba de la norma mundial de 105-106 varones por cada 100 niñas. Muchas de las "niñas desaparecidas" del campo están siendo adoptadas por extranjeros.

\section{Taiyuán}

Al oeste de Pekín, más allá de las montañas Taihán, se encuentra Taiyuán capital de la provincia de Shanxi. Aunque con un importante legado cultural, hoy en día Shanxi es sólo una provincia media dentro de China. Al conocer un poco de la historia de la provincia (cuna de la cultura china, ahí se estableció el primer centro budista del país, fue el antiguo centro de importantes familias comerciantes por encontrarse dentro de la ruta de la seda, lugar de establecimiento del primer banco de China, punto clave de la resistencia comunista contra los japoneses ${ }^{3}$, etc.) me preguntaba por qué Shanxi se ha quedado tan atrás durante la reforma.

Taiyuán es una ciudad mediana (para estándares chinos) donde el color dominante es el gris: está en la lista de las ciudades más 
contaminadas no sólo de China sino del mundo. Toda la provincia es en sí una mina de carbón, combustible de uso generalizado en toda China. A las afueras de Taiyuán puede uno ver las grandes chimeneas y las largas filas de camiones esperando ser cargados de carbón y coque. El carbón es también parte de la historia de Shanxi, sobre todo de la historia reciente de la provincia. Sus reservas de carbón fueron esenciales para llevar a cabo el plan maoísta de desarrollo de la industria pesada y siguen siéndolo para la creación de energía eléctrica y el abastecimiento de coque a la industria del acero.

Paradójicamente la importancia del carbón ha sido uno de los factores que han retardado el proceso de reforma en la provincia. $\mathrm{Al}$ constituir un recurso estratégico, el control sobre el mismo ha sido enormemente centralizado. El gobierno creó grandes empresas paraestatales para manejar su extracción y procesamiento, y mantuvo un control total sobre él hasta la década de los noventa. ${ }^{4}$ La transformación económica hacia una mayor liberalización y una diversificación de la propiedad de las empresas fue vista con ambivalencia en Shanxi. La reforma significaba la reestructuración de las empresas estatales, la eficientización de los procesos productivos y la búsqueda de mayor productividad; esto también significaba que había que despedir a mucha gente.

Hoy en día el gran miedo del Partido Comunista Chino (PCC) es la inestabilidad social y política que podrían causar grandes masas de desempleados. A fin de mantenerse en el poder, el PCC tendrá que asegurar el crecimiento económico, crear empleos suficientes para la sobreoferta de mano de obra o al menos asegurar los recursos económicos para mantener a flote a las empresas estatales y a sus trabajadores. En Taiyuán el progreso comienza a hacerse tangible: la construcción de modernos edificios y un número cada vez mayor de hoteles son reflejo de que el capital se está moviendo. Mientras tanto la industria del carbón colectiviza o privatiza procesos de extracción, producción, o transporte de este abundante recurso.

\section{Hangzhou}

Hangzhou, capital de la provincia de Zhejiang, es la ciudad con el mayor ingreso per cápita en China. Dentro de la provincia, sobre todo en Hangzhou, ha surgido un grupo de emprendedores que han consolidado un importante sector privado. Hangzhou, sin ser una ciudad cosmopolita, refleja su afluencia en la forma de vida de la nueva elite. La programación de los canales locales nos da una idea de los hábitos de consumo de los nuevos ricos, dirigidos en general al aspecto personal y a actividades recreativas. Las telenovelas nos dan también una idea de las aspiraciones de las nuevas elites. 'Ser moderno' no significa solamente adoptar un estilo de vida occidental; la ropa, la tecnología y los autos último modelo van de la mano con ideas y hábitos arraigados en la sociedad china. Por ejemplo, es interesante ver cómo la comida sigue teniendo un papel muy importante como marcador de estatus. El ser moderno y rico no significa solamente una variación en los hábitos alimenticios; la cantidad es también un aspecto importante. Es interesante ver las recurrentes imágenes de los protagonistas comiendo, ya sea en restaurantes o aun en casa. Hay que recordar que sólo 20 años atrás la comida era racionada y la variedad reducida. Aunque Hangzhou se encuentra a la sombra de Shanghai - mucho más cosmopolita y moderna-, sigue siendo considerada una de las ciudades más hermosas de China y en consecuencia una de las más visitadas.

La diversidad de China hace casi imposible dar una idea de lo que es este gran país, por lo que se tiende a caer en estereotipos para 
englobarlo y marcar las diferencias con Occidente. La descripción de cuatro ciudades con diferente localización geográfica nos da una imagen de dicha diversidad, aunque no expresa el contraste-mucho mayor- que existe entre el ámbito rural y las zonas urbanas. Algunas de las problemáticas de la ciudad reflejan esa dicotomía entre lo rural y lo urbano. Mientras tanto las disparidades se acrecentan, no sólo entre el campo y la ciudad, dentro de las propias ciudades. ${ }^{5}$ Sin ser el objetivo de este ensayo, se puede observar cómo gran parte de la problemática de las cuatro ciudades antes mencionadas tienen su origen en la creciente diferenciación económica entre regiones, pero también dentro del conglomerado urbano. De tal manera que la visión de China antes presentada nos da una noción de la complejidad del proceso de reforma, que como todo proceso representa algo en transición. Cierro entonces con el concepto de China como un fluido en búsqueda de una nueva forma, en la cual la influencia extranjera no arrasa sino que se transforma en lainteracción.

\section{Notas}

1 China tiene actualmente por mucho el mayor número de suicidios reportados a nivel mundial. Más de 300 mil personas $(42 \%$ del total de los suicidios a nivel mundial y $56 \%$ del total de los suicidios de mujeres a nivel mundial) se quitan la vida cada año. El $90 \%$ de los suicidios reportados se dan en zonas rurales, representando entre 600 y 800 suicidios diarios. Sing Lee y Arthur Kleinman. "Suicide as resistance in Chinese society". En Elizabeth Perry y Mark Selden. Chinese Society. Change, Conflict and Resistance. Routledge, 2000 p. 221

2 Tyrene White "Domination, resistance and accomodation in China's one-child campaign". En Elizabeth Perry y Mark Selden. Chinese Society. Change, Conflict and Resistance. Routledge, 2000 p. 113

3 Un análisis detallado del papel de esta provincia, no sólo en la Guerra de Resistencia sino también en la consolidación del movimiento comunista en el norte del país, puede encontrase en David S.G. Goodman Social And Political Change In Revolutionary China, Rowman \& Littlefield, 2000.

4 David Goodman "King Coal and Secretary Hu: Shanxi's Third Modernization". En Hans Hendrischke y Feng Chongyi. The Political Economy of China's Provinces: comparative and competitive advantage. Routledge, 1999.

5 Shaoguang Wang. "Openness and Inequality: Can China Compensate the Losers of its WTO Deal?" Seminario sobre Integración Regional en la Cuenca del Pacífico. El Impacto Económico. Sydney 23-24 julio, 2001.

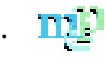

